\title{
Changing urban risk: 140 years of climatic hazards in New York City
}

\author{
Yaella Depietri $^{1}$ (D) Timon McPhearson ${ }^{1,2,3}$
}

Received: 31 October 2017 /Accepted: 18 March 2018

(C) The Author(s) 2019

\begin{abstract}
Weather-related disasters are on the rise. The causes, whether driven by climate change or changes in exposure and vulnerability of social-ecological-technological systems are still uncertain. Here, we address this issue with an in-depth study of the variability in climate-related extreme events which have impacted New York City (NYC) over the past 140 years. NYC has not historically been viewed as a particularly hazard prone region. However, this perspective is changing, particularly after the disastrous consequences of Hurricane Sandy (2012). We constructed a systematic database of impactful climatic events and assessed multi-sector impacts. Results indicate that hazards have systematically affected the city, with heat waves as the deadliest events and hurricanes as the costliest. We analyzed climatic hazard trends focusing on heat waves and flooding only, since data for these events are available over the full-time frame of the study. We then examined impacts of the most severe of these two hazards using data from The New York Times. Our analyses show that flooding and heat wave extreme events have regularly affected the city over its history with a trend toward increasing mean number of hazards per decade. We highlight a trend of decreased mortality due to heat waves over time and increase in the impacts of heavy precipitation, primarily related to the expansion of the transportation system and potentially to climate change over this time period. We suggest that, especially in urban areas of developed countries such as $\mathrm{NYC}$, changes in built up infrastructure may be the primary drivers of risk to natural hazards.
\end{abstract}

Electronic supplementary material The online version of this article (https://doi.org/10.1007/s10584-0182194-2) contains supplementary material, which is available to authorized users.

Timon McPhearson

timon.mcphearson@su.se

1 Urban Systems Lab, The New School, 79 Fifth Avenue, 16th Fl, New York, NY 10003, USA

2 Cary Institute of Ecosystem Studies, Millbrook, NY, USA

3 Stockholm Resilience Centre, Stockholm University, Stockholm, Sweden 


\section{Introduction}

Extreme climatic events are not new phenomena. However, increasing attention is being paid to the risk and vulnerability of social-ecological-technical systems (SETS) (McPhearson et al. 2016; Grimm et al. 2016) in particular in cities due to the increase of climate and geophysical disasters and their impacts (Guha-Sapir and Hoyois 2015). These hazardous events appear to be potentially driven by climate change together with the growing concentration of people and infrastructure in exposed urban areas (UNDESA 2014). The expansion of cities in hazard prone areas is a particularly worrisome trend in both developed and developing contexts, although with differing impacts related to the degree of development of the region (UNISDR 2013). In the USA, for example, recent devastating hurricanes including Hurricane Harvey, which damaged Houston (Texas) and Hurricane Irma, which devastated multiple Caribbean Islands including San Juan, Puerto Rico, demonstrate the vulnerability of coastal cities to such events. Many cities, which host a large proportion of the global human population, are located in low lying coastal zones and are likely to suffer from development intensification increasing the exposure of people, infrastructure and economic activity to coastal storms, and the effects of sea level rise (Neumann et al. 2015). Of course, it is not only coastal cities that are at risk. Cities around the world are more prone to suffer from extreme heat due to the combined impacts of the urban heat island, rising temperatures, and air pollution (IPCC 2015). However, increasing impacts of hazards in cities has been suggested to be linked to urbanization and expansion of infrastructure rather than driven by effects of climate change (Bouwer 2011). Still, research suggests that climate change may already be driving increased incidence of hazards worldwide (IPCC, 2014) and in the USA in particular, highlighted by the recent US National Climate Assessment (Melillo et al. 2014).

Understanding the occurrence and impacts of historical climatic hazards is critical to better interpret current hazard trends, impacts, and developing disaster risk reduction and long-term adaptation plans, especially in cities. An important question is, whether the occurrence of hazards has changed in the last decades, but also whether the impacts have changed and how.

Research is demonstrating that the impact of hazards is shifting, primarily because human and infrastructure vulnerability is shifting. For instance, the economic losses from cyclones have been climbing in developed, OECD countries much faster than in the rest of the world (UN 2011), signaling that exposure is changing. The advances in technology and reliance on engineered solutions may be accentuating risks in the long term. For example, when cities build dikes to reduce exposure to riverine floods, this can create a false sense of securitydriving populations to settle in unsafe areas and increasing risk (Leavitt and Kiefer 2006) (e.g., the case of Hurricane Katrina). The expansion of cities, assets, and infrastructures thus increases economic risk (UN 2011).

Despite recent global analyses, detailed examination of the change in hazards' impacts at the local level is virtually non-existent and represents a major missing knowledge base for disaster risk reduction (DRR) and climate change adaptation (CCA). To address this gap, we provided an in-depth case study of New York City (NYC) as an example of how a coastal megacity has been impacted by hazards in the recent history. We introduce this study by examining global and US trends in hazards' impacts since 1950. We then analyze the changes in the occurrence of climate-related hazards and of their impacts in NYC over the past 140 years. We build the most comprehensive database to date (to our knowledge) on hydrometeorological hazards occurrence as well as on their social and infrastructural impacts by combining existing hazard databases and mining data from news articles over the period 1876- 
2016 to assess social, economic, and infrastructure impacts. The hazards occurrence and impact database is meant to scientifically inform adaptation, resilience, and disaster reduction planning at the city, region, and federal level. The aim is then to detect any trends in hazards and impacts over time and reveal some of the key drivers of change in hazard impacts (including urbanization and climate change), focusing on two of the most impactful hazards affecting the city, heat waves and flooding. For a definition of hazard and disaster please see Supplement 1 .

\subsection{Disasters trends and distribution}

According to the Emergency Events Database (EM-DAT) of the Centre for Research on the Epidemiology of Disasters (CRED) (www.emdat.be), the number of deaths related to natural disasters has not increased since 1950, while the total number of people affected and the total monetary damages have been. Despite the increasing certitude of the change in climate, there is little agreement on whether the increased impacts of weather-related hazards can be attributed to climate change (Barredo 2009). Changes in exposure and vulnerabilities (see Supplement 1 for a definition) seem to be a significant reason determining increased risk and impacts of communities (Beniston 2007). Nonetheless, a global increase in annual maximum daily precipitation has been documented worldwide (Westra et al. 2013) as well as an increase in global temperature (Folland et al. 2001). The global SREX report on Extreme Weather Events of the IPCC (2012) states that it is very likely that there has been an increase in the number of warm days and warm nights. The report also affirms that, despite high regional variation, there are trends toward increasing days of heavy precipitation. Adaptation thus plays a key role in terms of the quality of institutional preparedness, coping, and response strategies, all of which can significantly limit deaths and losses (Toya and Skidmore 2007).

In the USA, the number of deaths (Fig. 1a) due to natural hazards has not increased and has instead declined over the past century, and yet the economic impacts have increased dramatically in the second half of the past century (Fig. 1b). Borden et al. (2007) show that the cities located in the eastern half of the USA have higher levels of physical and economic vulnerability when compared to their counterparts in the west and in the south, likely due to the concentration of cities on the Atlantic coast most exposed to coastal hazards, with NYC ranking as the fourth most vulnerable city.

\section{Methodology}

\subsection{Case study: New York City}

New York City is the largest city in the USA with about 8.5 million people in 2016, according to the U.S. Census Bureau, and the largest also in terms of economic activity. In the city live approximately 1.4 million elderly, age 60 and older, which constitute $17 \%$ of the population, and the proportion is projected to increase to $50 \%$ of the population in the next two decades (Goldman et al. 2014), driving greater risk of hazard impacts for this segment of the urban population. NYC is built around a network of rivers, estuaries, and islands with much of the Metropolitan region situated less than $5 \mathrm{~m}$ above mean sea level (MSL) (Colle et al. 2008). Three hazards that have historically caused high impacts in NYC are inland flooding, coastal 
Total deaths from natural hazards in the US from 1950-2017

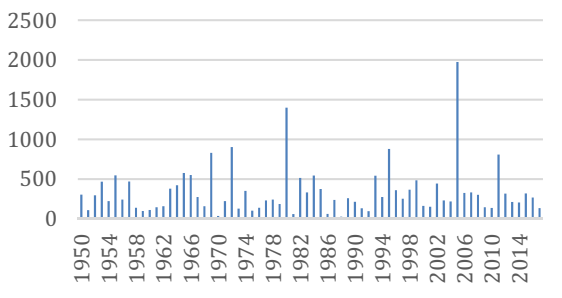

(a)
Total damage from natural hazards in the US from 1950-2017 in US\$

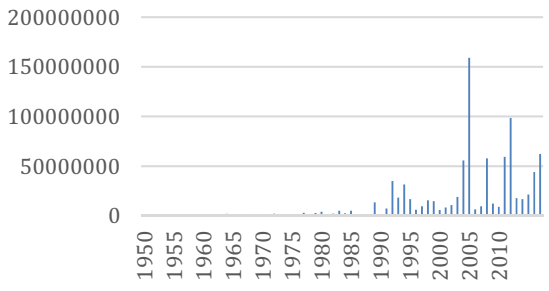

(b)

Fig. 1 a, b Total number of deaths (a) and total economic losses (b) due to natural hazards occurred in the USA between 1950 and 2017. The value of the estimated damage is given in the value of the year of occurrence (Source: EM-DAT, www.emdat.be)

flooding, and heat waves, with coastal flooding also caused by tropical storms and hurricanes. Overall, NYC climate is changing with higher temperatures, increasingly frequent heavy downpours, and a rising sea level (Rosenzweig and Solecki 2015). However, to date, there is no comprehensive database or analysis of the trends of multiple weather-related hazards and their impacts over time for NYC.

\subsection{The data and the methodology}

\subsubsection{Comprehensive database}

To build a comprehensive database of disasters that affected NYC in the past 140 years, we used multiple sources which described impactful hazards from the last decades of the nineteenth century onwards. The primary sources of data were from NOAA meteorological data that were then crosschecked with New York Times (NYT) articles (described in the next sections) to examine impacts; Weather 2000 (http://www. weather2000.com/ retrieved on the 6th of June 2017) for event data; the "NYC's risk landscape: a guide to hazard mitigation of 2014"; the "New York City Natural Hazard Mitigation Plan of March 2009"; and data provided in articles by Coch (2015) and Solecki (2012) for additional event and impact data. Despite our efforts to be comprehensive, we note that the total of 267 events likely remain an underestimation of the number of impactful and disastrous events that affected NYC in the past 140 years. Additionally, reliance on reporting in news articles is a potential limitation of our understanding of the full social, environmental, economic, and infrastructural impacts of hazards. Nonetheless, we have built a comprehensive database on historical hazards and impacts from what existing databases allow and report here trends in events and impacts over time.

\subsubsection{Extreme heat and extreme precipitation trends}

Local and regional definitions of hazards have been gathered and reviewed from the New York State (NYS) Department of Homeland Security and Emergency Services (DHSES) Standard 
Multi-Hazard Mitigation Plan (State Mitigation Plan) of 2014; the NYC Panel on Climate Change (NPCC) 2015 Report, Chapter 3 (Horton et al., 2015); the city of New York hazard mitigation plan 2014; and the NYC's Risk Landscape report, a guide to hazard mitigation (NYCEM, 2014). Given the available and reliable data on temperatures and precipitations constantly measured at Central Park and available on the NOAA agency portal (https://www. ncdc.noaa.gov/), we focused on extreme heat and extreme precipitation events to explore in depth climate-related hazard trends. We excluded from this analysis the rest of highly impactful hazards affecting NYC, such as tropical storms and hurricanes, since the freely available data from NOAA reported data on wind parameters in Central Park only starting from 2012.

For heat waves, we adopted the definition of the NPCC which defines such events as occurring over three consecutive days with maximum temperatures at or above $90{ }^{\circ} \mathrm{F}$ (about $32.2^{\circ} \mathrm{C}$ ). For floods, we adopted a precipitation threshold of $1.75 \mathrm{in}$. of rain since the city's drainage system is designed to handle heavy rainfall with intensities of 1.5 in. $(3.8 \mathrm{~cm})$ per hour in most areas of the city where sewers were built prior to 1960 , and of 1.75 in. $(4.4 \mathrm{~cm})$ per hour in locations with sewers were built after 1960 (Llyod and Licata, n.d.). Based on these definitions, significant extreme heat events and precipitation events were identified through the meteorological data for further analysis.

NOAA meteorological data was obtained for the station of Central Park (40.7889$73.9669^{\circ}$ ), located at $39.6 \mathrm{~m}$ of altitude, for the period going from January 1, 1876 to May 28, 2016. The quality of the meteorological data over time is thus consistent and likely not subject to bias.

Based on these data and the definitions of extreme heat and precipitation mentioned above, we identified the extreme heat and extreme precipitation events that affected NYC in the past 140 years. In total, 488 extreme precipitation beyond 1.75 in. of rain and 265 extreme heat events were identified. We then calculated trends in hazards features (i.e., temperature and duration for heat waves and intensity for extreme precipitation). We also calculated the changes in the hazards features from their average calculated between 1901 and 1960 (a procedure described in Horton et al. 2015). We also calculated the number of events per decade to detect changes in frequency.

\subsubsection{In depth analysis of the most severe events}

To further deepen our study, we concentrated on the most severe events identified among the NOAA meteorological data (i.e., heat waves which lasted 6 or more days - 37 events in total - and extreme precipitation events above 3.5 in. of rain- 51 events in total) and then compared this subset of events to reported events in newspaper articles to assess impacts. We examined relevant and corresponding newspapers articles in the New York Times (NYT). A similar methodology was applied by Barriendos and Rodrigo (2006). We searched articles 1 day following the date of the onset of the event and 2 days after its end date. We collected information about the main impacts of the selected events, additional information on their features and, where available, of coping strategies. We did notice a less systematic way of reporting impacts and losses due to extreme weather in newspapers articles after the second half of the twentieth century (possibly due to political reasons or questions of privacy) which may limit results on total impacts in recent decades. 


\section{Results}

\subsection{The database of hazards in NYC}

The results from the quantitative analysis of the database compiled in this study show that the most frequent impactful hazards that affect NYC are in the category of urban flooding followed by heat waves, hurricanes, and snowstorm (Fig. 2a). Among the list of hazards, the largest number of deaths in NYC is caused by heat waves, followed by hurricanes, and then tropical storms (Fig. 2b). Heat waves also caused the largest number of people injured or affected (Fig. 2c). Figure 2d shows that the largest economic losses are instead caused by hurricanes followed by tropical storms. A list of the 20 most impactful disasters in terms of deaths and a list of the 20 most impactful hazards in terms of economic losses that affected NY are presented in Supplement 2.

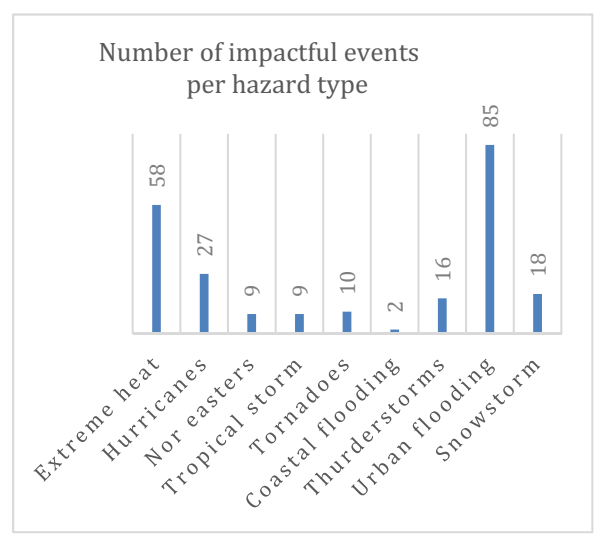

(a)

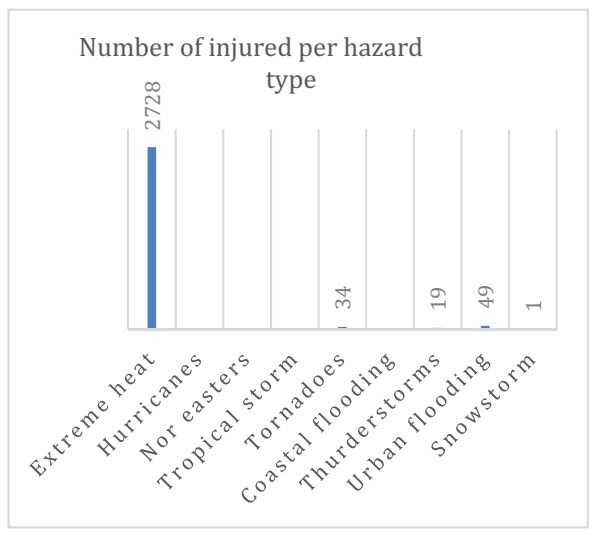

(c)

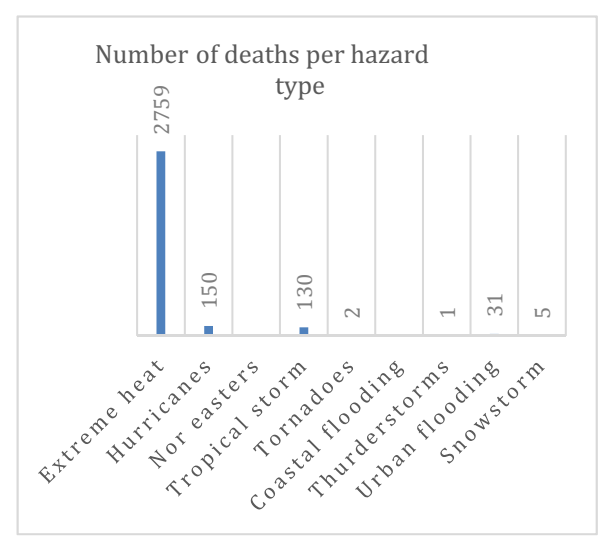

(b)

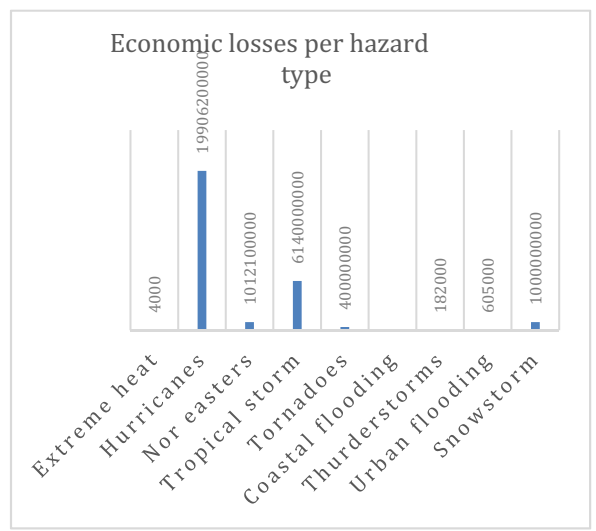

(d)

Fig. 2 a-d Number of impactful events (a), number of deaths (b) and number of injured (c) that occurred in NYC between 1876 and 2016 per hazard type. Total economic losses caused between 1876 and 2016 per hazard type (d) 
For trends in percentages of hydro-meteorological hazards deaths and injuries out of the total NYC population per decade, see Supplement 3.

\subsection{Trends extreme temperatures events and high precipitation events}

The trends based on the NOAA meteorological data show that changes in the length of the heat wave events equal or beyond 3 days of duration are not significant (Fig. 3 a). The mean maximum temperature of the heat wave is also close to stable over the 140-year period of study with no significant increase (Fig. 3b).

Figure 4a shows that the average maximum temperature of the heat wave per decade has shown inter annual and inter decadal variability. The length of the heat waves appears to be above normal for most of the period since the 1950s, although with significant interdecadal variability (see Fig. 4b). An increase in the number of heat wave events per decade can instead be detected since the 1930s (Fig. 4c).

Also not significant are the trends in extreme precipitation (beyond $1.75 \mathrm{in}$. and beyond 3.5 in.) with significant inter-annual and interdecadal variability (Fig. 5a, b).

There is no clear trend in changes in the intensity of the precipitation events equal or beyond 1.75 in. and (Fig. 6a) or equal or beyond 3.5 in. (Fig. 6b) which also present high interannual and interdecadal variability. Nonetheless, an increase in frequency of the extreme precipitation events with 1.75 in. of rain or more per decade is detectable (Fig. 6c).

\subsection{NOAA and the New York Times review}

\subsubsection{Major precipitation events}

The list of impacts identified by the NYT articles is summarized in Table 1. The numbers in the table correspond to the documenting of the impacts of the most extreme events in the newspaper articles. The unit corresponds to the appearance of the type of impact in the news article for a particular event. We found that the most impactful category, based on all impacts reported, are those affecting the transportation system. These include damages, delays, or closure of the subway system, as well as of trains, ferries, roads and highways, and impacts on transportation on air. It is not uncommon for New York City airports to close or cancel or delay flights due to

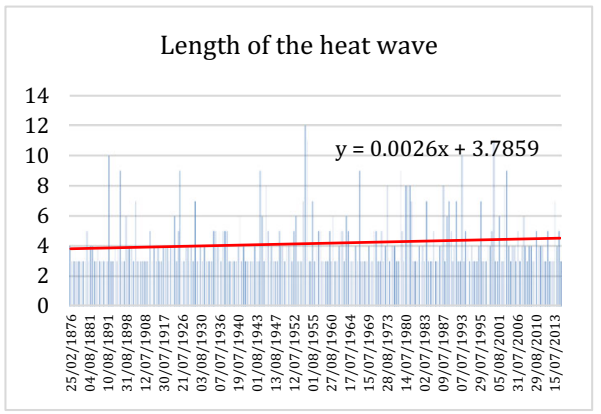

(a)

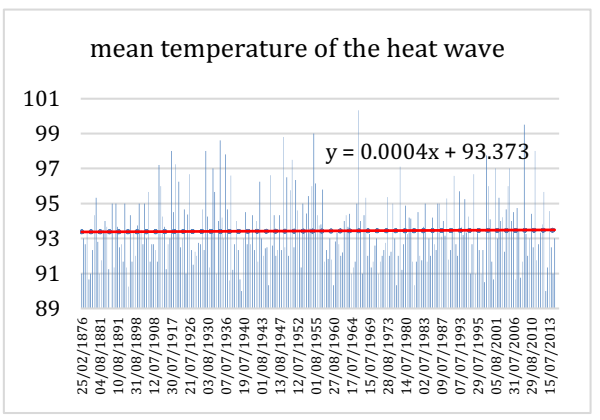

(b)

Fig. 3 a, b Length (a) and mean temperature (b) of heat wave events lasting at least 3 days or more in NYC from 1876 to end of May 2016 based on meteorological data collected at Central Park 


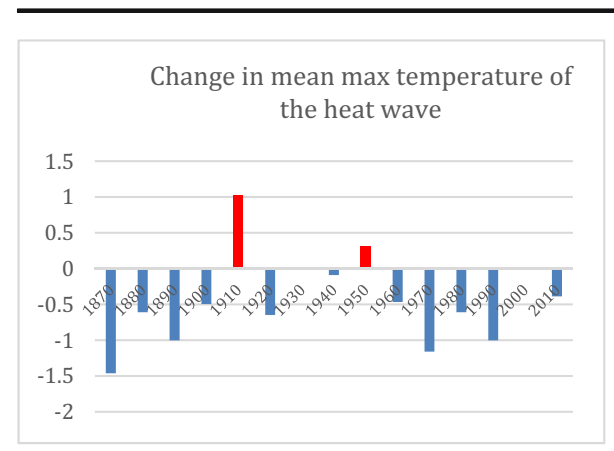

(a)

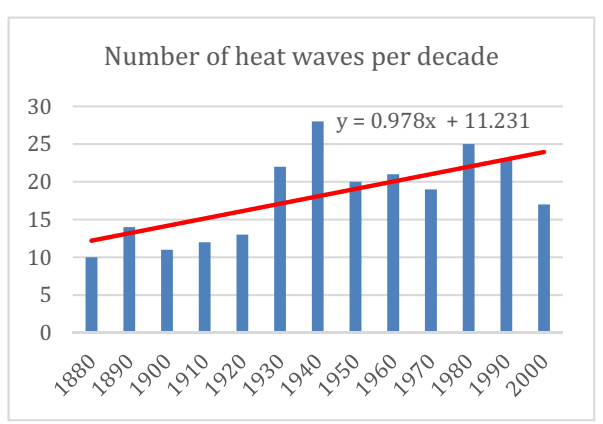

Change in the length of the heat wave

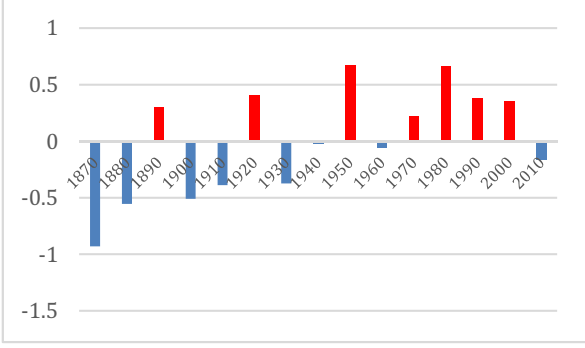

(b)

(c)

Fig. 4 a-c Changes in the mean max temperature (a) and length (b) of the heat waves lasting 3 days or more compared to the average max temperature calculated between 1901 and 1960 (a). Number of heat wave events per decade (c)

heavy rains. Extreme precipitation impacts to buildings, due to flooding and collapse, are also frequent impacts. Cellars and basement are those parts of the buildings that were more frequently flooded. Less frequent, but nonetheless significant, are the damages that occur to other infrastructure such as the energy system with frequent power outages, damages to the gas pipes, and overflow of the drainage system. In the more distant past, communications were affected as they

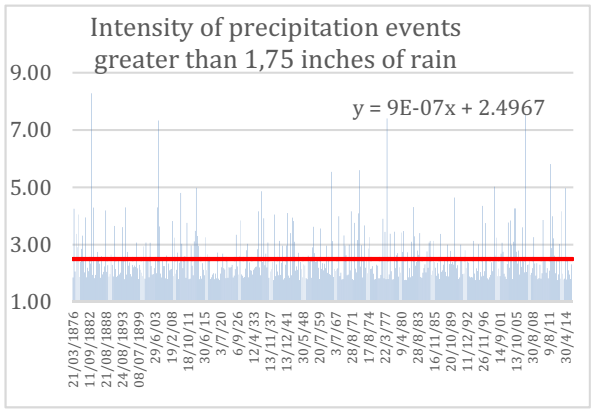

(a)

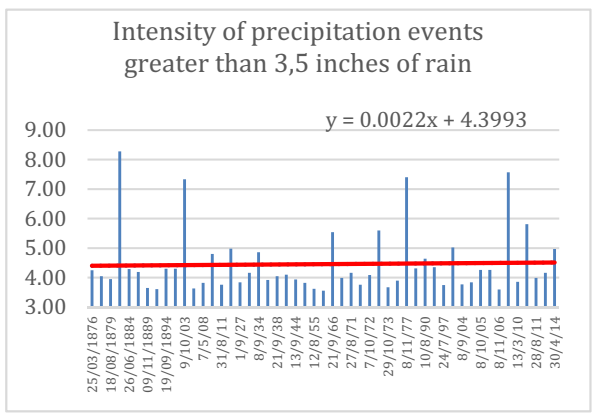

(b)

Fig. 5 a, b Precipitation trends for when it rained more than 1.75 in. of rain (a) and more than 3.5 in. of rain (b) in NYC as measured in Central Park between 1876 and 2016 (a) 


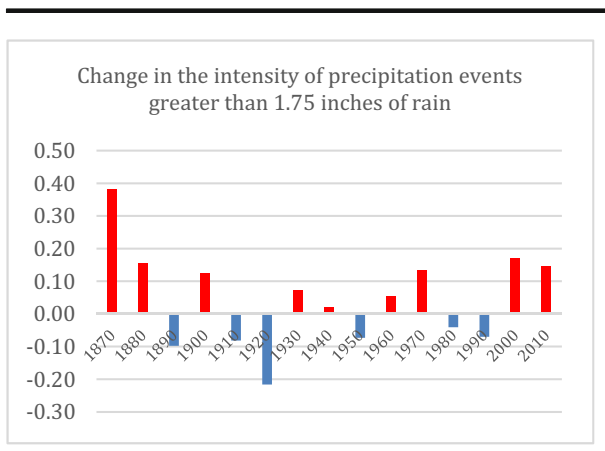

(a)

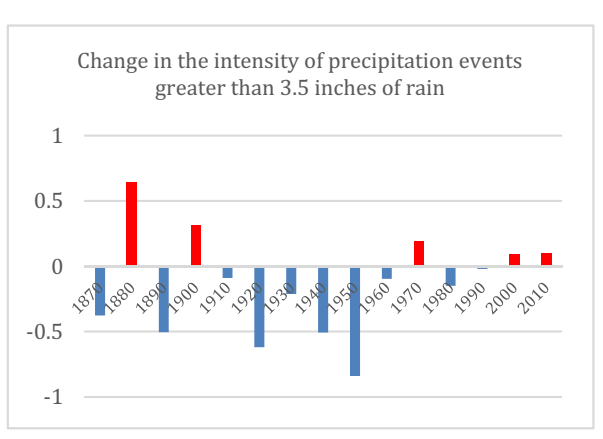

(b)

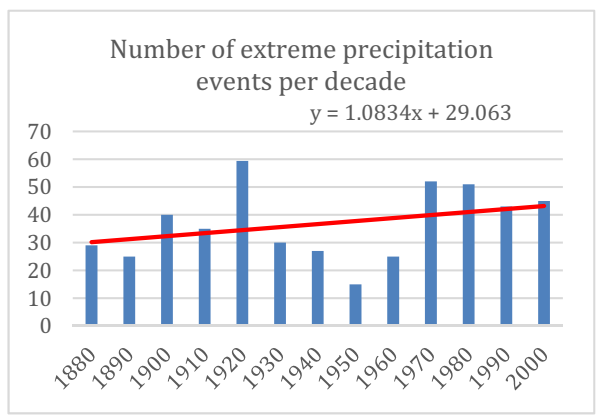

(c)

Fig. 6 a-c. Precipitation change per decade for events of 1.75 in. of rain or higher (a) and 3.5 in. of higher (b) compared to the mean calculated between 1901 and 1960. Number of precipitation events above 1.75 in. by decade (c).

relied on phone or telegraph lines. Also important are the damages to various kinds of green infrastructure such as trees, crops, and the coastal system of dunes. Finally, an important economic impact, but less frequent, are the damages to entertainment sector and the educational system due to closing of schools during extreme events.

Figure $7 \mathrm{a}-\mathrm{e}$ shows that trends in the categories of impacts due to heavy rain have been increasing significantly for the transportation sector while they have been remaining almost constant for the other impacts categories. A significant increase in the impacts to the subway system has been reported and can be attributed to the development of the subway, the train system, as well as on their aging. Of note is that the increase in the number of heavy rain events per decade because of climate change might also play a role in the increase of impacts. Impacts on other sectors do not show any significant negative or positive trend (Fig. 7c-e). In depth case studies of extreme precipitation events which occurred in NYC in different years are presented in Supplement 4.

\subsubsection{Extreme heat impacts}

Results obtained from the in-depth analysis of the NYT articles, corresponding to the dates of longer lasting heat wave events (i.e., equal or more than 6 days in duration), show that the number of deaths and people affected in New York City significantly declined (see Fig. 8). This is hypothetically due to the change in coping strategies which contributed to significantly 
Table 1 Summary of the damages, in terms of types and appearance in the NYT, for the selected major rainfall events (>3.5 in. of rain) that occurred in Central park since 1876

\begin{tabular}{|c|c|c|c|}
\hline Impacts & Number & Sector & Number \\
\hline Subway flooded and partly closed & 19 & Transportation & 93 \\
\hline Train traffic closed or delayed & 12 & & \\
\hline Ferry suspended & 1 & & \\
\hline Commuter delays & 5 & & \\
\hline Road traffic impeded & 19 & & \\
\hline Street flooding & 21 & & \\
\hline Road damaged & 4 & & \\
\hline Airport closure & 2 & & \\
\hline Flights delayed or canceled & 6 & & \\
\hline Car damaged & 3 & & \\
\hline Drown horses & 1 & & \\
\hline Cellars and basement flooded & 18 & Buildings & 45 \\
\hline Business flooded & 4 & & \\
\hline Buildings flooded & 5 & & \\
\hline Damages to buildings & 18 & & \\
\hline Sewage overflow/drainage system overwhelmed & 4 & Other infrastructures & 20 \\
\hline Power outages & 8 & & \\
\hline Damages to power lines & 2 & & \\
\hline Damages to the gas line & 2 & & \\
\hline Communication interrupted & 3 & & \\
\hline Other damages to infrastructures & 1 & & \\
\hline Fallen trees & 8 & Damages to green infrastructures & 19 \\
\hline Damages to the coast & 7 & & \\
\hline Damages to crops & 3 & & \\
\hline Oil spills & 1 & & \\
\hline Show industry affected & 2 & Entertainment and education & 6 \\
\hline Sports game canceled & 3 & & \\
\hline Schools closed & 1 & & \\
\hline
\end{tabular}

reduce mortality, primarily thanks to the diffusion of air conditioning and the availability of cooling centers (see Table 2). At the end of the nineteenth century and beginning of the 20th, the city would distribute ice to the poorer populations during heat waves. People would also move in mass to the seashore, take a ferry to State Island, for example, and crowd parks, or take a train out of the hot city. The change in coping strategies mentioned in the newspapers articles and divided before and after the 1960s illustrates how the advent of air conditioning can be most likely contributed to the significant reduction in mortality due to extreme heat. Linked to that is however the increase risk of power outages which often occurs due to heat stress in the city. The impacts of heat waves in New York City are thus not new, and important lessons can be learned from the past as temperature and the length of the heat waves are trending higher.

For extreme heat too, in-depth case studies which occurred in NYC in different years are presented in Supplement 4.

\section{Discussion and conclusions}

We compiled, from multiple sources to build a comprehensive database of hazards and impacts which affected New York City in the past 140 years. The database allowed us to identify the 

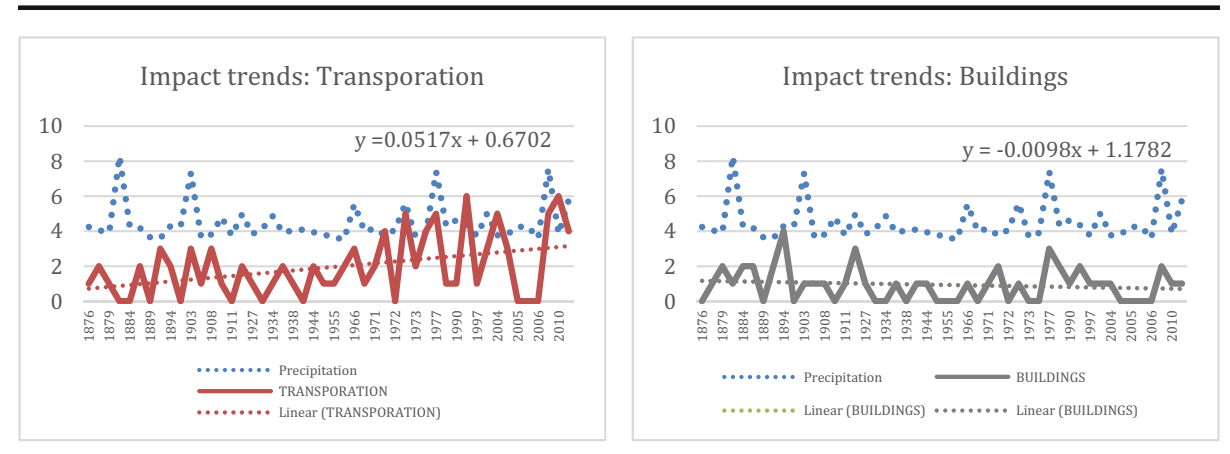

(a)

(b)
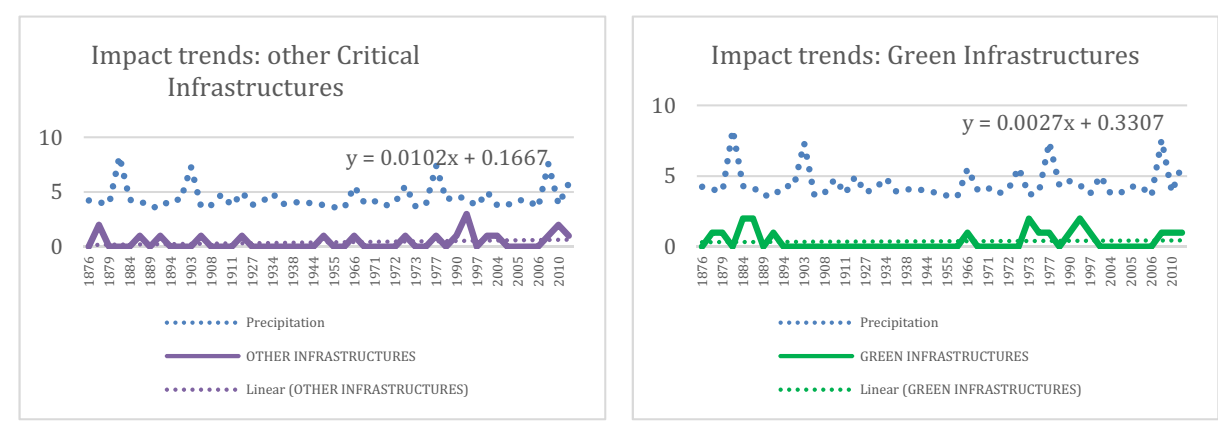

(c)

(d)

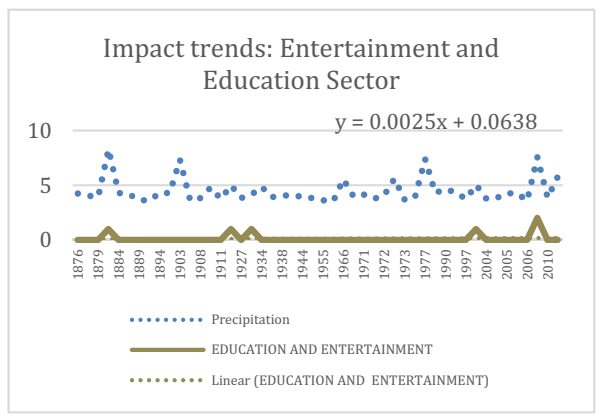

(e)

Fig. 7 a-e Trends in the impacts on the transportation system (a), on building (b), on critical infrastructures (c), on green infrastructures (d), and on the entertainment and education sector (e) based on the NOAA/NYT semiquantitative review.

most frequent hazards (i.e., urban flooding and heat waves) and the most impactful hazards (i.e., heat waves in terms of mortality and morbidity, and hurricanes and other coastal storms in terms of economic losses) that affected NYC from 1876 to 2016. We then narrowed the study and analyzed the major trends in the occurrence of high precipitation and extreme heat events that affected NYC between 1876 and 2016. These results do not show significant upward or downward trends; however, they become relevant to mention when compared to the other results obtained from the study. Although intensity of the heat and flood hazards did not change significantly, the number of events increased both for heat waves and for flooding. 


\section{Number of death and people affected by heat waves in NYC between 1876 and 2016}

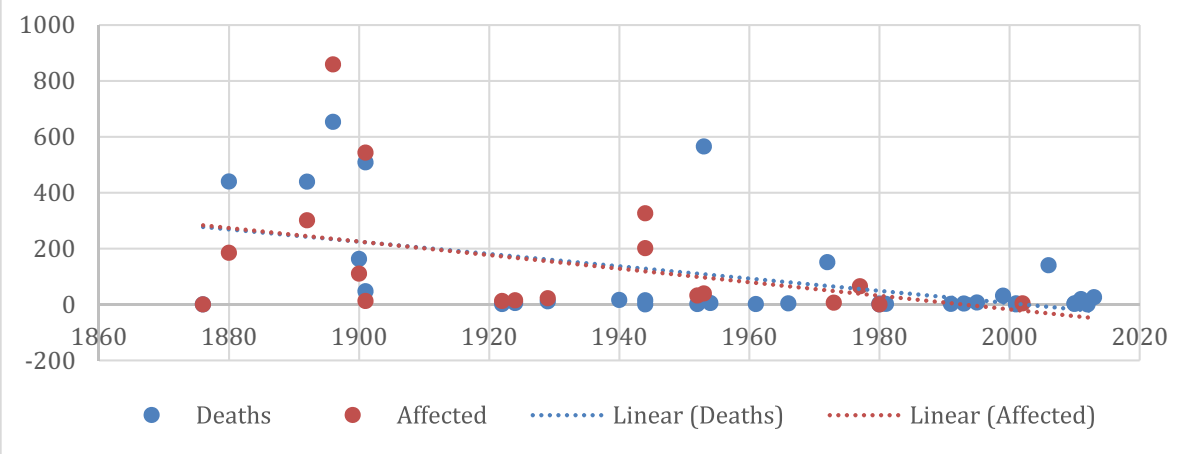

Fig. 8 Trends in the number of death and number of affected by heat waves as derived from heat wave events affecting NYC in the past 140 years

While intensity only showed some variability, frequency increased for extreme precipitation and extreme heat. A more in-depth analysis of the impacts of these hazards showed a significant decrease in the impacts of heat waves and an increase in impacts of heavy precipitation on the transportation system. These results suggest that, in NYC, changes in exposure and vulnerability outpace changes in the hazards intensity both for inland flooding and heat waves respectively. The increase of heavy precipitation events, may also be attributed, to some extent, to climate change due to the increase in the frequency of the events.

In the case of heat waves, the significant decrease in mortality and morbidity can be associated with a change in the coping and adaptation strategies, with the introduction of air conditioning (see also Petkova et al. 2013). In this context, power outages become the main threat to the new conditions. To note is that these changes occurred despite and in concomitance with the increase in frequency and of the hazardous events.

We empirically demonstrated how the social-ecological-technological (SET) component of the hazard needs to be a central component of understanding drivers of risk to natural hazards. Results suggest that the role of infrastructures in disaster risk reduction and climate change adaptation in a megacity of the developed world is central. Whether it's in relation to the need to reduce the exposure of the expanding transportation system to heavy precipitation or the need to improve energy supply to cope with heat waves, critical infrastructures in high risk areas of cities of the developed world play a preponderant role which has outpaced, in most instances, the change in

Table 2 List of coping strategies to extreme heat before and after the 1960s

Before 1960s

- Offices would close earlier

- People would leave the city for the countryside

- Most people at the beach, others at the parks that would be kept open also during the night

- Turn hydrants on

- Distribute ice
After $1960 \mathrm{~s}$

- Uncapping fire hydrants

- Visiting parks and beaches (if no pollution alert); beaches and pools open at night

- Buy fans and air conditioning

- Visiting cool places like supermarkets, other stores, cinemas, theaters, libraries, subways

- Indoor ice skating 
climate and related impacts occurring so far. The empirical case studied substantiates the argument that changes or increases in the impacts of extreme hydro-meteorological events in urban areas are principally driven by the change and expansion of infrastructures in urban areas, despite the increase in the number of extreme precipitation events and of extreme heat events per decade. We suggest that, to improve resilience to hazardous events, cities will need to address underlying drivers of builtup infrastructure and social-economic conditions to create cities that are less socially and infrastructurally vulnerable. This means perhaps major changes in urban form and urban development, zoning, and land use changes as well as improving equity in access to infrastructure, including green infrastructures (see McPhearson 2017), and services that can decrease exposure and increase coping and adaptive capacity to hazards. It will be increasingly important for climate change adaptation to be treated as part of a broader effort toward the reduction of risk to hazards, especially in urban environments.

Acknowledgements The authors are grateful to Bart Orr and Jerome Frost for their contribution in the gathering of the data and two anonymous reviewers for their insightful comments.

Funding information Timon McPhearson is supported by the Urban Resilience to Extreme Weather-Related Events Sustainability Research Network (URExSRN; NSF grant no. SES 1444755).

Open Access This article is distributed under the terms of the Creative Commons Attribution 4.0 International License (http://creativecommons.org/licenses/by/4.0/), which permits unrestricted use, distribution, and reproduction in any medium, provided you give appropriate credit to the original author(s) and the source, provide a link to the Creative Commons license, and indicate if changes were made.

Publisher's Note Springer Nature remains neutral with regard to jurisdictional claims in published maps and institutional affiliations.

\section{References}

Barredo JI (2009) Normalised flood losses in Europe: 1970-2006. Nat Hazards Earth Syst Sci 9:97-104. https://doi.org/10.5194/nhess-9-97-2009

Barriendos M, Rodrigo FS (2006) Study of historical flood events on Spanish rivers using documentary data. Hydrol Sci J 51:765-783. https://doi.org/10.1623/hysj.51.5.765

Beniston M (2007) Linking extreme climate events and economic impacts: examples from the Swiss Alps. Energy Policy 35:5384-5392. https://doi.org/10.1016/j.enpol.2006.01.032

Borden KA, Schmidtlein MC, Emrich CT, Piegorsch WW, Cutter SL (2007) Vulnerability of U.S. cities to environmental hazards. J Homel Secur Emerg Manag 4. https://doi.org/10.2202/1547-7355.1279

Bouwer LM (2011) Have disaster losses increased due to anthropogenic climate change? Bull Am Meteorol Soc 92:39-46. https://doi.org/10.1175/2010BAMS3092.1

Coch NK (2015) Unique vulnerability of the New York-New Jersey metropolitan area to hurricane destruction. J Coast Res 299:196-212. https://doi.org/10.2112/JCOASTRES-D-13-00183.1

Colle BA, Buonaiuto F, Bowman MJ, Wilson RE, Flood R, Hunter R, Mintz A, Hill D (2008) New York City's vulnerability to coastal flooding: storm surge modeling of past cyclones. Bull Am Meteorol Soc 89:829-841. https://doi.org/10.1175/2007BAMS2401.1

Folland CK, Rayner NA, Brown SJ, Smith TM, Shen SSP, Parker DE, Macadam I, Jones PD, Jones RN, Nicholls N, Sexton DMH (2001) Global temperature change and its uncertainties since 1861. Geophys Res Lett 28: 2621-2624. https://doi.org/10.1029/2001GL012877

Goldman L, Finkelstein R, Schafer P, Pugh T (2014) Resilient communities: empowering older adults in disasters and daily life. The New York Accademy of Medicine

Grimm N, Cook EM, Hale RL, Iwaniec DM (2016) A broader framing of ecosystem services in cities: benefits and challenges of built, natural, or hybrid system function. In: Seto KC-Y, Solecki W, Griffith C (eds) The Routledge handbook of urbanization and global environmental change. Routledge, Taylor \& Francis Group, New York 
Guha-Sapir D, Hoyois P (2015) Estimating populations affected by disasters: a review of methodological issues and research gaps. In: Centre for Research on the epidemiology of disasters (CRED). Université catholique de Louvain, Institute of Health and Society (IRSS)

Horton R, Bader D, Kushnir Y, Little C, Blake R, Rosenzweig C (2015) New York City panel on climate change 2015 report. Chapter 1: climate observations and projections: NPCC 2015 report chapter 1. Ann N Y Acad Sci 1336:18-35. https://doi.org/10.1111/nyas.12586

IPCC (2015) Climate change 2014: synthesis report. Intergovernmental panel on climate change (IPCC), Geneva, Switzerland

IPCC (2014) Climate Change 2014 Synthesis Report Summary for Policymakers, IPCC 5th Assessment Report. Intergovernmental Pannel on Climate Change (IPCC)

IPCC (ed) (2012) Managing the risks of extreme events and disasters to advance climate change adaption: special report of the intergovernmental panel on climate change. Cambridge University Press, New York, NY

Leavitt WM, Kiefer JJ (2006) Infrastructure interdependency and the creation of a normal disaster: the case of hurricane Katrina and the City of New Orleans. Public Works Manag Policy 10:306-314. https://doi. org/10.1177/1087724X06289055

Llyod E, Licata A (n.d.) One new York City: one water. Sustainable water managemnet for New York City's people and environment

McPhearson T (2017) Hurricanes: enlist nature's protection. Nature 550:43-43. https://doi.org/10.1038/550043c

McPhearson T, STA Pickett N, Grimm J, Niemelä M, Alberti T Elmqvist C et al (2016) Advancing urban ecology toward a science of cities. BioScience 66(3):198-212. https://doi.org/10.1093/biosci/biw002

Melillo JM, Richmon TTC, Yohe GW (Eds.) (2014) Climate change impacts in the United States, highlights: U.S. national climate assessment. US Global Change Research Program

Neumann B, Vafeidis AT, Zimmermann J, Nicholls RJ (2015) Future coastal population growth and exposure to sea-level rise and coastal flooding - a global assessment. PLoS One 10. https://doi.org/10.1371/journal. pone. 0118571

NYCEM (2014) NYC's risk landscape: a guide to hazard mitigation. New York City Emergency Management, Department of City Planning and Mayor Office of Recovery and Resiliency

Petkova EP, Horton RM, Bader DA, Kinney PL (2013) Projected heat-related mortality in the U.S. urban northeast. Int J Environ Res Public Health 10:6734-6747. https://doi.org/10.3390/ijerph10126734

Rosenzweig C, Solecki W (2015) New York City panel on climate change 2015 report introduction: NPCC 2015 report introduction. Ann N Y Acad Sci 1336:3-5. https://doi.org/10.1111/nyas.12625

Solecki W (2012) Urban environmental challenges and climate change action in new York City. Environ Urban 24:557-573. https://doi.org/10.1177/0956247812456472

Toya H, Skidmore M (2007) Economic development and the impacts of natural disasters. Econ Lett 94:20-25. https://doi.org/10.1016/j.econlet.2006.06.020

UN (2011) Global assessment report on disaster risk reduction. United Nations international strategy for disaster reduction, Geneva, Switzerland

UNDESA (2014) World urbanization prospects: the 2014 revision, United Nations Department of economic and social Affairs. United Nations

UNISDR (2013) From shared risk to shared value - the business case for disaster risk reduction. Global assessment report on disaster risk reduction. United Nations Office for Disaster Risk Reduction (UNISDR), Geneva

Westra S, Alexander LV, Zwiers FW (2013) Global increasing trends in annual maximum daily precipitation. J Clim 26:3904-3918. https://doi.org/10.1175/JCLI-D-12-00502.1 